\title{
Visibilidade compulsória e moralidade feminina: reflexões sobre gênero a partir das práticas de pornografia de vingança
}

\author{
Roberta de Sousa Mélo \\ Universidade Federal do Vale do São Francisco \\ Rafael de Oliveira Rodrigues ${ }^{2}$ \\ Universidade Federal de Alagoas \\ Alvaro Rego Millen Neto 3 \\ Universidade Federal do Vale do São Francisco
}

Resumo: Este ensaio se insere no cenário das preocupações teóricas acerca do consumo, criação e compartilhamento de conteúdos disponibilizados nas mídias digitais. A partir de uma pesquisa documental, analisamos o conteúdo de publicações e comentários em redes sociais e de matérias e reportagens online sobre as práticas de pornografia de vingança (divulgação não autorizada de imagens e vídeos íntimos), buscando compreender as associações simbólicas construídas em torno do comportamento feminino. Nossos resultados demonstram a importância das mídias digitais enquanto campo de estudo das relações generificadas de poder e seus efeitos na corporeidade feminina.

Palavras-chave: corporeidade feminina; mídias digitais; pornografia de vingança; vídeos íntimos; violência de gênero.

\footnotetext{
${ }^{1}$ Possui graduação em Ciências Sociais pela Universidade Federal de Pernambuco, mestrado e doutorado em Sociologia pela mesma instituição. Atualmente é professora adjunta 1 da UNIVASF, onde atua no Programa de Pós Graduação em Educação Física (PPGEF. Autora do livro Da visibilidade dos corpos disformes: um estudo sobre cirurgias cosméticas mal sucedidas (Editora Universitária/UFPE).

2 Professor Adjunto I na Universidade Federal de Alagoas (UFAL). Doutor e mestre em Antropologia pelo Programa de Pós-Graduação em Antropologia Social da UFSC). Cientista Social pela Universidade Federal de Pernambuco (UFPE)

3 Doutorado em Educação Física na Universidade Gama Filho (2013). Atualmente é Professor Adjunto do Colegiado Acadêmico de Educação Física da Universidade Federal do Vale do São Francisco (UNIVASF).
} 


\title{
Compulsory visibility and female morality: reflections on gender from revenge porn practices
}

\begin{abstract}
This essay is inserted on theoretical concerns about the consumerism, creation and sharing of contents available on digital medias. Based on documentary research, we analyzed the posting and comments of social networks, as well as articles and online news reports, about revenge porn practices (the release of unauthorized images and intimate tapes), searching to understand symbolic associations built around the feminine behavior. Our results show the importance of digital media as a field of study of gendered relations of power and its effects in female corporeity.
\end{abstract}

Keywords: digital medias; female corporeity; gender violence; intimate videos; revenge porn.

\section{Visibilidad compulsiva y moralidad femenina: reflexiones sobre género a partir de las prácticas de porno de venganza}

\begin{abstract}
Resumen: Este ensayo se inserta en el escenario de las preocupaciones teóricas acerca del consumo, creación y compartición de contenidos disponibles en los medios digitales. Basado en investigación documental, se analizó el contenido de publicaciones y comentarios en redes sociales y de materiales y reportajes online sobre las prácticas de porno de venganza (la divulgación no autorizada de imágenes y videos íntimos), buscando comprender las asociaciones simbólicas construidas en torno al comportamiento femenino. Los resultados demuestran la importancia de los medios digitales como campo de estudio de las relaciones generalizadas de poder y sus efectos en la corporeidad femenina.
\end{abstract}

Palabras clave: corporación femenina; medios digitales; porno de venganza; videos íntimos; violencia de género. 
$\mathrm{A}$ s questões que aqui trazemos remetem inevitavelmente à trajetória patriarcal e seus mecanismos históricos de controle do corpo, da subjetividade da sexualidade das mulheres. Nosso tema de estudo indica reelaborações dessa opressão, partindo da ideia de que as relações estabelecidas nas redes sociais digitais se constituem como campo profícuo para analisarmos essas atualizações, considerando seus impactos nas formas de comunicação e interação social que caracterizam a contemporaneidade. As formas de sociabilidade mediadas pelas novas tecnologias trazem importantes debates e disputas morais e ideológicas que podem ser pensadas a partir de marcadores sociais característicos das reflexões socioantropológicas: classe, gênero, geração, raça, etnia, dentre outros. A nosso ver, trata-se de um campo de estudo proeminente no que diz respeito aos modelos comportamentais que orientam as interações de seus usuários (MILLER e SLATER, 2011). É preciso reconhecer que nossas interações têm sido cada vez mais mediadas pelas imagens, o que nos remete ao regime do espetáculo vislumbrado por Guy Debord (1997). Nesse sentido, sob todas as suas formas de produção e consumo, a espetacularização seria o modelo de existência dominante, e o espetáculo da imagem a forma hegemônica de afirmação da vida humana. Sob esse viés, a cultura imagética analisada por Debord estabelece um vínculo fundamental entre o ter e o parecer; uma preocupação cada vez mais proeminente com a afirmação da aparência de acordo com os códigos e signos de visibilidade socialmente organizados.

Nas novas redes de sociabilidade, territórios da hipervalorização da imagem pessoal, remetemos nossos corpos e subjetividades ao escrutínio da audiência, ao mesmo tempo em que também somos espectadores da "produção de si" alheia. A construção da autoimagem é recompensada pelos likes atribuídos aos conteúdos que compartilhamos. Com a popularização dos smartphones e aplicativos de celular, efeito da expansão do próprio capitalismo de consumo, esses conteúdos são compartilhados numa velocidade inédita. O poder de consumo é, aqui, uma variável importante para entendermos determinadas relações de poder embutidas na fabricação de imagens e nos modelos de subjetivação enaltecidos pelo capitalismo contemporâneo. Afinal, como nos lembram Richard Miskolci (2016), Suely Fragoso, Raquel Recuero e Adriana Amaral (2011), as caracterizações da nossa sociedade digital indicam não apenas rupturas e novidades, mas também continuidades e aprofundamentos de fenômenos previamente abordados pela antropologia e pela sociologia. Do mesmo modo, relações assimétricas de gênero também são reproduzidas nas evocações à publicização cotidiana do eu que demarca os usos das redes sociais. Se pela nossa tradição histórica patriarcal a esfera privada foi determinada como ambiente feminino por primazia, nos parece que as tensões entre o âmbito público e a corporeidade, subjetividade e sexualidade femininas se atualizam pelos nossos regimes atuais de visibilidade. As práticas conhecidas como revenge porn traduzem bem essas permanências que coexistem com as novas formas de interação entre os gêneros, revelando formas compulsórias e violentas de exposição de imagens das mulheres e, portanto, a violação de sua intimidade. Elas revelam um processo pelo qual a própria cultura imagética e as di- 
nâmicas de visibilidade vigentes são apropriadas para dar continuidade à opressão de um grupo historicamente em desvantagem, considerando-se a organização social de gênero que tem legitimado esses desníveis de poder.

O termo em questão pode ser traduzido como "pornografia de vingança", referindo-se à divulgação não autorizada de imagens e vídeos íntimos, conforme Mariana Giorgetti Valente, Natália Neris, Juliana Pacetta Ruiz e Lucas Bulgarelli (2016), geralmente por parte de ex-parceiros. De acordo com os autores, não se trata de um problema recente, mas ele ganhou novas dimensões com a popularização da internet e sua capacidade de fazer repercutir os conteúdos compartilhados. No que diz respeito a casos emblemáticos veiculados pela mídia brasileira, uma reportagem publicada em um site se refere às histórias de duas adolescentes que, no ano de 2013, se suicidaram após terem vídeos íntimos divulgados nas redes sociais. As jovens utilizaram essas mesmas plataformas de comunicação para deixar mensagens de despedida 4 . No mesmo ano, a campanha \#SomosTodasFran foi promovida por feministas como forma de reação e apoio à outra jovem que teve sua intimidade exposta a partir do intenso compartilhamento de um vídeo nas redes sociais. Dois anos antes, a atriz brasileira Carolina Dieckmann teve seu computador invadido por criminosos virtuais, que passaram a tentar extorqui-la sob a ameaça de divulgar fotos em que ela aparecia nua. O caso deu origem à lei 12.737/2012 (Lei Carolina Dieckmann), que passou a criminalizar "a invasão de computadores para obter vantagem ilícita, como a falsificação de cartões de crédito e a interrupção de serviço telegráfico, telefônico, informático, telemático ou de informação de utilidade pública" (GIONGO, 2015: 7). Entretanto, conforme as análises citadas por Marina Grandi Giongo, a lei não trata especificamente da divulgação criminosa de conteúdo íntimo. A legislação em torno dessas práticas ainda é, portanto, bastante incipiente. Beatriz Accioly Lins (2015) destaca os Projetos de Lei propostos a partir de 2013 pelo senador Romário e pelo deputado João Arruda (PMDB/PR). O senador Romário também criou em suas redes sociais, no ano de 2015, uma campanha para tirar do ar o clipe da música "Eu vou jogar na internet", gravada pela dupla sertaneja Max e Mariano, alegando tratarse de apologia à prática de pornografia de vingança. $\mathrm{O}$ fato teve grande repercussão entre o público. Uma semana após o lançamento, o clipe foi retirado do Youtube, e todos os canais oficiais da dupla na internet chegaram a ser deletados 5 .

Evidenciando as relações de poder que estão por trás das estatísticas desse tipo de crime, as organizações feministas têm dado maior visibilidade à temática, fomentando discussões e elaborando redes de apoio contínuo às vítimas. É o caso da campanha \#mandaprints, idealizada pela OLGA, uma ONG feminista criada em 2013, que define como sua missão "empoderar mulheres por meio da informação e retratar as ações delas em locais onde a voz dominante não acredita existir nenhuma mulher"6. A convocatória destaca que a internet não deve ser entendida como lugar de impunidade. Sendo assim, estimula que as vítimas denunciem a violência virtual sofrida, orientando-as quanto aos procedimentos a serem adotados. A campanha também alerta para a necessidade de pressionar os órgãos públicos de modo a darem maior relevância ao problema.

\footnotetext{
4 Foram amplamente divulgados pela mídia brasileira os casos de suicídio de duas jovens menores de idade, em 2013, vítimas de divulgação não autorizada de material íntimo. Ver em: <http://www1.folha.uol.com.br/cotidiano/2013/12/1379100-exposicao-sexual-na-internet-se-alastra-e-causa-vitimas.shtml > Acesso em 7 de abril de 2017. Ver também matéria "Como um sonho ruim", publicada em 19 de dezembro de 2013. Disponível em <http://apublica.org/2013/12/6191/> Acesso em 7 de abril de 2018.

5 Ver matéria "Após música sobre pornô de vingança, dupla Max \& Mariano retira páginas das redes sociais", publicada em 08 de abril de 2015. Disponível em <http://www.diariodepernambuco.com.br/app/noticia/divirtase/46,51,46,61/2015/04/o8/internas viver,570394/apos-musica-sobre-porno-de-vinganca-dupla-max-mariano-retira-paginas-das-redes-sociais.shtml> Acesso em 7 de abril de 2018.

${ }_{6}^{6}$ Ver $<$ https://thinkolga.com/2018/01/30/manda-prints $>$. Acesso em 7 de abril de 2018.
} 
É preciso frisar que homens também são vítimas da pornografia não consensual. Ainda assim, a prática atinge preponderantemente as mulheres. De acordo com dados fornecidos pela ONG SaferNet Brasil (organização dedicada a monitorar e combater a violação de direitos humanos na internet, em parceria com a Polícia Federal e o Ministério Público), 81\% das vítimas atendidas eram mulheres e, a cada quatro, uma era menor de idade 7 . São diversas as consequências negativas desse tipo de exposição: assédio, perda de emprego, abandono da escola ou faculdade, isolamento social, além de danos emocionais e traumas psicológicos, mostrando as relações complexas entre as experiências mediadas pelas ferramentas comunicacionais em rede e seus impactos na vida cotidiana corporificada dessas pessoas. Tendo em vista as problemáticas anunciadas, o objetivo deste ensaio é analisar e compreender as representações e associações simbólicas construídas em torno do comportamento e da corporeidade feminina a partir de publicações e comentários em redes sociais e de matérias e reportagens online sobre as práticas de pornografia de vingança.

No que se refere à metodologia utilizada para dar suporte a este estudo, a exemplo de Ana Rigoni, Felipe Nunes e Katia Fonseca (2017), o que prevalece nesta pesquisa é a preocupação com os significados atribuídos pelas pessoas que compartilham os conteúdos referentes ao nosso tema. Estamos considerando, portanto, as relações entre os sujeitos, a partir de suas interpretações e das representações construídas nas relações sociais num sentido mais amplo. Nessa direção, a busca documental, condição basilar dessa pesquisa, foi realizada em diversos sites da internet que noticiaram casos de pornografia de vingança, no período de janeiro a dezembro de 2017, sendo selecionados conteúdos publicados a partir do ano de 2013, período em que esses casos começaram a ganhar maior evidência na internet. Todos os comentários analisados foram compartilhados em modo público, ou seja, acessível a qualquer usuário da rede. Ao percebermos como os comentários mobilizavam questões morais e explicitavam construções culturais em torno da corporeidade e do comportamento das mulheres, procuramos aprofundar as análises, reconhecendo, mais uma vez, o quanto as interações em rede refletem as experiências e relações estabelecidas na vida cotidiana corporificada. Ao revelarem relevantes representações construídas a respeito da relação entre as construções de gênero e a corporeidade, esses conteúdos evidenciam sua importância para os campos do conhecimento interessados na expressão corporal e suas diversas interfaces.

A princípio, foi realizada uma busca em bases de dados como o Google, priorizando matérias e reportagens cujos comentários estivessem disponíveis ao público. Os conteúdos também foram pesquisados nos compartilhamentos em redes sociais, como o Facebook, sobretudo a partir das hashtags, que são palavraschave utilizadas como indexadores nas redes sociais, tendo como propósito o compartilhamento de um determinado tema (no caso, fizemos a busca pela hashtag \#revengeporn e \#pornografiaderevanche), como também em revistas sobre temas diversos e veículos de notícias online. Em seguida, realizamos uma análise dos comentários e impressões dos usuários da internet, dos consumidores das notícias e dos relatos veiculados nas páginas selecionadas.

\footnotetext{
7 Ver matéria "Em 2 anos, $\mathrm{n}^{\circ}$ de vítimas de imagens íntimas vazadas quadruplica" publicada em o6 de julho de 2015. Disponível em <http://brasil.estadao.com.br/noticias/geral,numero-de-vitimas-de-imagens-intimas-vazadas-na-webquadruplica-em-2-anos,1719799>. Acesso em 7 de abril de 2018.
} 


\title{
Redes sociais digitais e violência de gênero
}

Também concentrada nas estruturas generificadas que permeiam a prática da pornografia de vingança, Giongo (2015) salienta que o uso da expressão não abrange irrestritamente qualquer caso de veiculação não autorizada de imagens íntimas, já que nem sempre a prática se caracteriza como retaliação contra a mulher após o fim de um relacionamento. Em algumas situações, como alerta a autora, não há nenhum tipo de envolvimento pessoal com a vítima.

\begin{abstract}
A organização internacional End Revenge Porn esclarece que a terminologia mais precisa para enquadrar todos os casos é "pornografia não-consensual", caracterizada como a distribuição de imagens sexualmente gráficas de indivíduos sem o seu consentimento. Isto inclui tanto as imagens originalmente obtidas sem o conhecimento da vítima (por exemplo, através de câmeras e webcams escondidas, telefones celulares roubados, computadores hackeados, a gravação de agressões sexuais por terceiros, etc.), bem como imagens obtidas consensualmente dentro do contexto de um relacionamento íntimo. O conteúdo pode ser utilizado para prejudicar a vítima tanto por excompanheiros inconformados com uma traição ou pelo simples término do relacionamento, quanto por hackers oportunistas que ameaçam ou divulgam o material sem que a pessoa saiba para obter algum tipo de vantagem. Quando há a intencionalidade, as formas de chantagem configuram tortura psicológica extrema, incluindo especialmente ameaças de exposição das fotos para membros da família, empregadores(as), colegas de trabalho, escola ou faculdade. (GIONGO, 2015: 7)
\end{abstract}

Considerando as diferenças trazidas por Giongo quanto aos usos do termo, ressaltamos que o foco principal serão os casos de revenge porn, sem, no entanto, deixar de perceber e mencionar a violência que se faz presente nas práticas de pornografia não consensual e de vingança de modo geral. Em ambos os casos, estamos lidando com formas de manutenção de uma opressão histórica. Contudo, considerando os dados de uma pesquisa realizada pela Organização Mundial de Saúde em conjunto com a London School of Hygiene and Tropical Medicine, a qual mostrou que aproximadamente $35 \%$ dos assassinatos de mulheres no mundo todo foram cometidos por parceiros íntimos (MEDEIROS e TAVARES, 2017), os contornos específicos em se tratando de violências nas relações de intimidade se evidenciam.

Esse recorte também permite trazer de modo mais enfático elementos relacionados aos significados e às apropriações do corpo, do emocional e da sexualidade da mulher estipulados pelo regime patriarcal: numa trajetória histórica em que as relações são mobilizadas por uma perspectiva falocêntrica, tendo a realização masculina como núcleo central, essas dimensões se configuram como alvo de controle por excelência (MEDEIROS e TAVARES, 2017).

Tomando como norte teórico a abordagem de gênero de Joan Scott (1990), a qual nos possibilita entender o caráter relacional das diferenças entre homens e mulheres, entendemos essas representações de masculinidade e feminilidade enquanto processos mobilizados pela organização social das diferenças sexuais percebidas. Desse modo, a autora propõe atenção aos "sistemas de significados, isto é, às maneiras como as sociedades representam o gênero, o utilizam para articular regras de relações sociais ou para construir o sentido da experiência" (SCOTT, 1990: 15).

A violência da pornografia de vingança está fundada nos jogos relacionais entre homens e mulheres estipulados pelas nossas regulamentações de gênero atuais que, no entanto, reproduzem elementos de um antigo modelo de organização social que tem garantido a hegemonia de determinadas experiências de masculinidade em detrimento da opressão das mulheres. Entretanto, consideramos, a partir de Scott (1990), que essa dimensão relacional é historicamente variável, ou 
seja, os modos como homens e mulheres se constituem e se relacionam entre si são instáveis, transitórios e complexos, uma vez que as significações atribuídas pela cultura às diferenças sexuais percebidas também se realizam num tempo e espaço determinados (MATOS, 1997), evidenciando, assim, a necessidade de historicização das percepções das diferenças sexuais e das relações estabelecidas a partir delas. Assim, entendemos que as relações de gênero mediadas pelas plataformas comunicacionais em rede trazem especificidades do nosso momento atual, com consequências políticas e subjetivas que só fazem sentido se considerarmos os valores a que o surgimento, desenvolvimento e usos dessas tecnologias estão relacionados.

\section{O novo apedrejamento em praça pública: a popularidade como um castigo}

Os casos que analisaremos apontam uma relação de poder marcante: tem-se a prática de um ex-parceiro (com quem a vítima conviveu intimamente por algum tempo ou num momento específico) para quem a perda de controle sobre a mulher se constitui como ameaça à sua honra, adotando, assim, uma atitude fiel ao entendimento do corpo e da subjetividade feminina como campo da dominação masculina. No que diz respeito à pornografia de vingança, é através do constrangimento da mulher que esse poder se instaura e é reiterado. A exposição compulsória reafirma a dicotomia inaugurada pelo pensamento civilizacional moderno que associava a dignidade da mulher ao seu confinamento na vida doméstica, ao passo que o mundo público sempre foi legitimado como domínio masculino. Entretanto, mesmo em suas experiências mais íntimas, sua vida é invadida pelos códigos sociais e perpassada pela rigidez moral. Nesse caso, ocorre um processo pelo qual as práticas privadas se tornam objeto publicável, como forma de condenação das mulheres de comportamento desviante. No âmago da motivação para a pornografia de vingança reside a distinção entre a mulher para se estabelecer compromisso e a "mulher fácil", culpabilizada pela própria exposição e consequente morte social. A propósito, o alcance desse tipo de estratégia só pode ser explicado se levarmos em consideração a criação desses estigmas.

Além disso, a maneira como o corpo e as identidades femininas são socialmente compreendidas em nossos esquemas atuais de generificação favorece, muitas vezes, a reafirmação de uma cultura do assédio que normaliza e relativiza violências físicas e simbólicas dirigidas às mulheres, muitas vezes culpabilizadas pela própria opressão sofrida, exatamente porque a elas cabe, de acordo com essa lógica, o resguardo e a responsabilidade pelo próprio corpo. É na esfera da corporeidade e da moralidade que incide essa forma de vingança.

Instruída por uma moral patriarcal cristã, a vida sexual feminina, reduzida ao seu papel reprodutivo, é cercada por tabus e experiências afetivas como culpa e pudor. Essa rigidez aparece de modo marcante na experiência de uma das adolescentes que se suicidaram após serem vítimas de vazamento de conteúdo íntimo, de acordo com a mensagem deixada por uma delas em suas redes sociais e conforme a declaração de amigos e parentes em reportagem já mencionada na introdução: 
Ela disse pra prima que não queria que a família sentisse vergonha e sofresse por um erro dela. A nossa família é bem conhecida, e a cidade é pequena, meio bocuda, bastante gente inventa coisas. Às vezes você faz uma coisinha e acabam aumentando ${ }^{8}$.

Há uma relação notória entre a eficácia do vazamento de conteúdo íntimo e a lógica patriarcal que ainda fundamenta a instituição familiar como o modelo pelos quais os vínculos afetivos e sociais são estabelecidos e mantidos em nossa cultura (o que não significa negar que tal modelo não esteja em permanente transformação), e pelo qual as mulheres continuam subjugadas e sexualmente reprimidas. A eficácia e os danos causados por esse tipo de prática também incidem sobre outros domínios da subjetividade feminina, como a maternidade, por exemplo. A experiência abaixo revela como os mecanismos de culpabilização das vítimas ganham ainda mais força ao associarem o comportamento feminino ao comprometimento da figura materna, cercada por estereótipos que a definem como uma missão sagrada que exige devoção incondicional aos filhos. Todas essas construções potencializam o efeito da chantagem e reiteram a criminalização da sexualidade feminina.

\begin{abstract}
O meu filho acabou indo para outro país - ficou seis anos no exterior -, porque não suportou tudo isso. Chegou a pedir para mudar de nome, que eu o deixasse a algumas quadras da escola para que não soubessem que eu era sua mãe. A minha filha mais nova também sofreu demais. Tive de mudá-la de escola muitas vezes, porque ela chorava e dizia que não queria mais voltar. Perdi o emprego, sofri um processo de exclusão social, fui quase linchada na cidade. ${ }^{9}$
\end{abstract}

Se o patriarcado é um regime que tem como base a dominação das mulheres pelos homens (SAFFIOTI, 2015), não é fortuito que os praticantes da pornografia de vingança estejam cientes dos padrões que as imagens de suas vítimas abalarão. Numa relação em que sua posse é culturalmente legitimada, a desqualificação da mulher se torna um trunfo.

A relação com a própria sexualidade é, por excelência, uma das bases primordiais das construções de gênero em nossa cultura. Isso pode explicar, ao menos em parte, o motivo pelo qual os homens são menos atingidos por essas práticas em específico. Afinal, eles são, desde os primórdios de sua socialização, estimulados a cultivar sua virilidade. Ainda persistem práticas sociais que o induzem à iniciação sexual como forma de afirmação de si. Nesse sentido, o temor exposto na mensagem de despedida da jovem que se suicidou após ser vítima da prática, por exemplo, dificilmente seria uma preocupação para um rapaz da mesma idade que ela. Não queremos dizer, com isso, que a situação de vazamento da intimidade não traria nenhum constrangimento ou sofrimento a ele. Porém, a exposição da sua vida sexual não destoaria do modelo comportamental que lhe é socialmente atribuído ${ }^{10}$. Ao contrário, o desempenho sexual se constitui como símbolo indispensável de sua formação subjetiva. Os prostíbulos, por exemplo, continuam sendo espaços de construção desse ethos masculino. Assim, a sexualidade se constitui como experiência social pela qual se delegam posições assimétricas a homens e mulheres. Marca de reconhecimento cultural para eles, mecanismo de exclusão social para elas.

${ }^{8}$ Ver matéria "Como um sonho ruim", publicada em 19 de dezembro de 2013: < http://apublica.org/2013/12/6191>. Acesso em 7 de abril de 2018.

9 Ver matéria "O que difere a pornografia de vingança dos outros crimes é a continuidade", publicada em 16 de fevereiro de 2016. Disponível em <http://www.nucciber.mpba.mp.br/o-que-difere-a-pornografia-de-vinganca-dos-outros-crimese-a-continuidade/>. Acesso em 7 de abril de 2018.

${ }^{10}$ Obviamente estamos considerando, aqui, as experiências sexuais que atendem aos padrões heteronormativos. 
De fato, tanto em alguns comentários em defesa das vítimas de pornografia de vingança como nos que as culpabilizam pelo ocorrido, o tema da "responsabilidade por si mesma" apareceu de forma marcante. Algumas falas enfatizam que esse senso de cuidado deve se sobrepor ao que parecem considerar "armadilhas" do narcisismo estimulado por uma cultura de valorização da aparência e da espetacularização de si:

\begin{abstract}
Sobre a facilidade que as pessoas encontram em se expor, acho que é porque elas têm sido conduzidas a dar prioridade a seus prazeres imediatos, mesmo que isso lhes custe posteriormente uma vida de sofrimento, vídeos desse tipo evidenciam muito claramente isso. Maior consciência disso faria com que prazeres fugazes não fossem prioridade na vida de uma pessoa que irá continuar após o tal prazer ter passado. Mas, na construção da sociedade atual não há o desejo por conter-se, ao contrário, deseja-se quebrar todos os limites. Paga-se o preço (isso explica o quadro, mas não justifica os ataques à quem foi exposto e a condescendência com o crime de expor alguém). [Postado pela leitora Tatiana em matéria compartilhada pelo site Papo de Homem em 17 de dezembro de 2015].
\end{abstract}

Sem desconsiderar a gravidade da ação do divulgador das imagens íntimas, a comentarista compreende a necessidade de uma gestão de si nos usos das novas tecnologias comunicacionais. Nesse sentido, destaca a ação individual como elemento importante para se evitar transtornos como os causados pela prática de pornografia de vingança. A fala acima traz, assim, os mecanismos de exibição de si como importante vetor dos processos de decisão individual, lócus proeminente da racionalidade e reflexividade do sujeito contemporâneo.

Em outras narrativas, a ênfase deixa de ser dada à violação praticada e se faz de modo a destacar ou a ingenuidade ou a negligência da mulher para com ela mesma e sua privacidade, como ilustra o seguinte comentário: "Acho que a mulher deve se preservar e evitar de mandar fotos nuas. A gente nunca conhece realmente a pessoa que está do outro lado da linha”. [Postado pela leitora Luiza, em matéria compartilhada pela revista Marie Claire, em 16/07/2014].

Em julho de 2014 a revista Marie Claire - de publicação mensal e voltada para o público feminino - divulgou uma matéria sobre a decisão da justiça mineira de reduzir o valor da punição de praticantes de pornografia de vingança, alegando a parcela de culpa da jovem que teve imagens íntimas divulgadas:

\begin{abstract}
Na primeira instância, a juíza Andreísa Alves decidiu condenar o réu, um analista de sistemas, ao pagamento de indenização de $\mathbf{R} \$ 100$ mil por ex-namorada. Ao chegar ao tribunal, no entanto, a decisão se reverteu. Dois dos desembargadores que analisaram o caso entenderam que a vítima colaborou "de forma bem acentuada e preponderante" para o crime e reduziram o valor da punição para $\mathrm{R} \$ 5$ mil.
\end{abstract}

A matéria traz também trechos da justificativa dos magistrados:

\begin{abstract}
A vítima dessa divulgação foi a autora [da ação] embora tenha concorrido de forma bem acentuada e preponderante. Ligou sua webcam, direcionou-a para suas partes íntimas. Fez poses. Dialogou com o réu por algum tempo. Tinha consciência do que fazia e do risco que corria [...] escreveu o relator Francisco Batista de Abreu ao justificar sua decisão, reiterada pelo colega Otávio de Abreu Portes ${ }^{11}$.
\end{abstract}

Ao inaugurar novas formas de visibilidade dos corpos e estimular a espetacularização da imagem pessoal, as plataformas comunicacionais atuais mobilizam, ao mesmo tempo, a reconfiguração das fronteiras morais entre o público e o privado, sendo que essa moralidade se dirige mais incisivamente à corporeidade $\mathrm{e}$

\footnotetext{
${ }^{11}$ Ver matéria "Justiça de Minas Gerais culpa jovem que teve imagens íntimas divulgadas na internet por se expor", publicada em 14 de julho de 2014.

Disponível em < http://revistamarieclaire.globo.com/Mulheres-do-Mundo/noticia/2014/o7/justica-de-minas-geraisculpa-jovem-que-teve-imagens-intimas-divulgadas-na-internet-por-se-expor.html $>$. Acesso em 7 de abril de 2018.
} 
sexualidade femininas. Percebe-se, a partir do trecho acima, que a prática de pornografia de vingança atribui uma demanda que se constitui como eminentemente feminina pelos arranjos de gênero que lhe dão sentido: no caso, a vigilância sobre o corpo e sobre a intimidade. Trata-se de uma preocupação historicamente destinada à mulher. Sob essa lógica, a corporeidade e a sexualidade se constituem como domínios aos quais se remetem ameaças externas que devem ser evitadas pela própria mulher, conforme sugere a fala do relator. Ao mesmo tempo, as narrativas acima nos dão ideia da expansão do problema, o qual parece não se esgotar na violência praticada, já que essa parece reiterada pelos valores androcêntricos que norteiam o âmbito em que foi julgada. Nesses casos, a culpabilização da mulher vitimada foi legitimada numa instância que, como se sabe, estabelece parâmetros oficiais e normas que guiam nossas interações cotidianas. Esse é, portanto, um ponto fundamental para se compreender o circuito de relações de poder que opera para a reprodutibilidade de assimetrias de gênero em que ele próprio está fundamentado.

A atribuição dessa responsabilidade à vítima foi criticada por uma leitora na seguinte fala: "É lamentável que se tenha desembargadores com um pensamento tão atrasado, machista. [...] Esse tipo de gente é que pensa que a vítima do estupro também é culpada. Que sociedade é essa?” [Postado pela leitora Eliana, em 22/08/2014].

O risco aparece como uma categoria importante nos direcionamentos dados aos usuários para o uso adequado da internet. Em nosso levantamento de materiais para este estudo, não foram raras as matérias de caráter preventivo que traziam orientações de especialistas sobre como não ter sua intimidade violada. $\mathrm{O}$ compromisso moral em racionalizar os perigos e evitá-los também foi percebido nas análises de Giongo (2016: 11), num estudo que teve como foco principal de análise comentários publicados em matérias sobre casos de pornografia de vingança envolvendo jovens de uma cidade do sul do país. Dentre as narrativas selecionadas pela autora, podemos destacar o comentário postado por uma leitora do site em que as práticas foram divulgadas: "Se não quer que as fotos vazem na internet é só não tirar. Agora não adianta querer se matar, devia ter pensado antes de tirar foto pelada pra mandar pro namoradinho".

Algo semelhante também foi sugerido por um usuário nas redes sociais da Prefeitura de Curitiba-PR, a respeito de uma campanha de combate à violação da intimidade promovida pelo órgão. Através do projeto, foram enviados vídeos e fotos por WhatsApp, em que se lia a mensagem "Se não é pra você é melhor não ver. Compartilhar fotos íntimas também é crime. Denuncie. Ligue 180”. Um dos leitores, então, opinou:

\footnotetext{
A partir do momento que você faz um vídeo mostrando o seu rosto você tem que ter a consciência de que esse vídeo pode vazar, não intencionalmente, mas o celular da pessoa pode ser roubado, o vídeo pode estar em um computador e esse ser roubado, enfim existem possibilidades desse vídeo vazar. Filmou, mandou e vazou não reclame você sabia dos riscos. [Postado pelo usuário Rodrigo na página do Facebook da Prefeitura de Curtiba-PR, em 11 de julho de 2015].
}

Há, portanto, uma tendência a localizar na ação da vítima a origem da violência sofrida por ela mesma. Vê-se um jogo conflituoso em torno da autonomia feminina: ao mesmo tempo em que é responsável pelo seu corpo, a expressão de sua sexualidade faz com que os constrangimentos e punições a ela dirigidos sejam relativizados e mesmo justificados. É válido lembrar que parte significativa dos comentários que se concentraram na moralidade da vítima, não levando em conta 
as assimetrias de gênero que legitimam esse tipo de prática, partiu de outras mulheres. As narrativas abaixo foram publicadas em resposta ao compartilhamento de uma matéria do jornal $O$ Estado de $S$. Paulo no site de notícias Uol ${ }^{12}$ :

\begin{abstract}
E vai piorar muito antes de melhorar... Liberdade feminina no Brasil é sinônimo de libertinagem! Liberdade tem que acompanhar responsabilidade! [Postado pela leitora Maria, em 2016]

Infelizmente existem mulheres que não servem para nada e usam o corpo como mostruário. Elas não têm moral para reclamar do vazamento das fotos. [...] O pior de tudo é que ficam se fazendo de vítima e o Estado é paternalista com estas tralhas. Quanto vazar as fotos lembro do ditado: se entrou na chuva é para se molhar. Como mulher sinto-me enojada ao ver que a minha categoria está criando estas mocinhas sem valores [...]. [Postado pela leitora Solange, em 2016]
\end{abstract}

O problema, então, não é encarado como uma questão coletiva ou de interesse comum às mulheres, passível de ser vivenciado por qualquer uma, inclusive por elas mesmas: ao contrário, ele é atribuído a posturas individuais e morais. Ao mesmo tempo, essa atitude individual é criticada e culpabilizada como uma ação que compromete a reputação de todo um grupo, como sugere a última fala. A respeito desses conflitos, podemos remeter às observações feitas por Heleieth Saffioti (2015), ao reconhecer que a abordagem de gênero proposta por Scott (1990) se estende para as relações entre mulheres e outras mulheres. É nesse sentido que a autora pensa a categoria mulher como relacional, a partir de seus processos de construção e reciprocidade entre homens e outras mulheres. Nesse sentido, situações de opressão também são socialmente autorizadas e estimuladas entre elas. O caráter variável e contextual atribuído às relações de gênero, conforme sugere Scott, nos é útil para perceber precisamente como se sustentam nossos mecanismos de regulação das diferenças entre homens e mulheres e que relações os beneficiam: um deles, como podemos perceber, é a internalização, por partes das mulheres, dos próprios padrões comportamentais que as oprimem, assim como a culpabilização entre elas. Esse é um fator crucial para a eficiência da pornografia de vingança, por exemplo.

Na mesma publicação, visualizamos um comentário que revela certo abrandamento em relação a não intencionalidade da vítima em ser exposta nas redes:

\begin{abstract}
Tiram as fotos porque querem, permitem que tirem, facilitam tudo, acham lindo qdo são as "pessoas" que querem que vejam etc. etc. etc. Sejam homens ou mulheres - não importa. Fazem porque querem se exibir e confiam porque tb querem confiar. Criem vergonha na cara. Só vale a grita qdo as fotos ou vídeos são feitas de forma clandestina. Nestes casos acima relatados o que faltou foi vergonha na cara. [Postado pela leitora Maíra, em 2016, sobre matéria do jornal O Estado de S. Paulo compartilhada no site de notícias Uol]
\end{abstract}

Existe, então, uma carga de julgamento em torno da vítima no que concerne à exposição de sua imagem pessoal. Se, pelas nossas redes, somos estimulados a mostrar o melhor de nós, o comprometimento da imagem que passamos também é de nossa responsabilidade. Curiosamente, nesses discursos, não se exige uma racionalização e ponderação dos riscos por parte de quem divulga e compartilha esses materiais. Mesmo em alguns discursos em que a análise intenta tratar o problema como uma questão de educação familiar, sua origem é mais uma vez apontada na moralidade feminina. A educação masculina e os padrões de comportamento a que os homens são socialmente motivados não são incluídos, tampouco problematizados na abordagem abaixo:

12 Disponível em <https://noticias.uol.com.br/ultimas-noticias/agencia-estado/2015/07/06/numero-de-vitimas-deimagens-intimas-vazadas-na-web-quadruplica-em-2-anos.htm > Acesso em 7 de abril de 2018. 
As famílias têm que saber dialogar com as suas filhas, pois tenho a certeza de que se fossem bem aconselhadas, pensariam duas vezes antes de se exporem. O que pode ajudar um pouco é a família fiscalizar o facebook das suas filhas, para avaliar se as mesmas estão com uma postura e roupas adequadas e na desconfiança colocar limites e sempre avaliar as amizades. [Trecho do comentário postado pela leitora Cristiane sobre matéria do jornal O Estado de S. Paulo compartilhada no site de notícias Uol]

A assimilação do discurso da responsabilidade de si, socialmente instituída, converte-se em um sentimento de culpa que tem sido apontado como um dos fatores que inibem a denúncia por parte das vítimas, conforme aponta um número considerável de matérias e reportagens a que tivemos acesso. Para muitas, o ato de denunciar seria o equivalente a prolongar o próprio constrangimento e sofrimento. Vê-se, então, que os efeitos da exposição íntima não consensual são persistentes. Considerando-se, sobretudo, a capacidade proliferativa das plataformas comunicacionais, com sua supressão de barreiras temporais e espaciais, as marcas da pornografia de vingança podem ser permanentes.

Mais do que meramente acessados, os registros da intimidade alheia podem ser armazenados e reassistidos inúmeras vezes. Nesse sentido, as interações em rede se configuram como meios de impressão do estigma da mulher envolvida, da constante lembrança de sua mácula, passível de ser acessada a qualquer momento, como sugere as experiências de vítimas de pornografia de vingança descritas em matérias publicadas em revistas:

\begin{abstract}
As sentenças judiciais, muito mais que o dinheiro, ajudam a cicatrizar feridas como a de Bruna. Quando conversou com Marie Claire pela primeira vez, ela descreveu sua rotina - uma vida praticamente analógica. Os e-mails eram reduzidos ao trabalho. A internet, um território temido que ela preferia evitar. Contou não usar MSN e redes sociais. Na segunda conversa, no entanto, descreveu uma vitória. "Consegui fazer um perfil de Facebook", disse, entusiasmada com a conquista. "O fato de a Justiça tê-lo condenado me fez sentir mais leve, mais livre". No mínimo uma vez por mês, ela rastreia a internet à procura do seu nome, com medo do que o Google possa mostrar na tela do computador ${ }^{13}$.

É ilusão você falar que o que está na internet vai ser deletado um dia. O que está na internet nunca vai sair. O que difere a pornografia de vingança dos outros crimes é a continuidade. É como se alguém lhe desse uma facada e ficasse lá, remoendo, e a cicatriz nunca se fechasse. O crime que se viraliza traz consequências terríveis, o atentado contra a honra se perpetua ali na rede internacional de computadores. O dano é irreparável, as consequências são imensuráveis ${ }^{14}$.
\end{abstract}

Numa realidade de relações sociais cada vez mais mediadas pelas plataformas comunicacionais, pode-se sugerir que houve uma ruptura no cotidiano da primeira das informantes acima, a qual vai além das possíveis perdas nas relações presenciais (trabalho, estudo, relacionamentos afetivo-sexuais). A abdicação de sua antiga "rotina digital" se fez junto ao reconhecimento de novas formas de manejar os riscos a que ela se refere. Mas, como ela própria aponta, ainda que se veja capaz de racionalizá-las melhor, essas ameaças não deixarão de existir.

As relações presenciais e as relações mediadas pela conectividade se refletem mutuamente, assim como as violências produzidas em cada um desses contextos se tocam diretamente e ecoam entre si. Contudo, é sempre válido destacar: os efeitos da violência que estamos analisando são desproporcionais; esse tipo de vingança só faz sentido diante dos arranjos de gênero e dos padrões de sexualidade do contexto cultural em que ocorre.

13 Ver matéria "Sexo, vingança e vergonha na rede - expostas por seus ex, elas dão o troco na justiça”. Disponível em < http://revistamarieclaire.globo.com/Revista/Common/o,,ERT259500-17737,oo.html>. Acesso em 7 de abril de 2018. 14 Ver matéria “O que difere a pornografia de vingança dos outros crimes é a continuidade”, publicada em 16 de fevereiro de 2016. Disponível em http://www.nucciber.mpba.mp.br/o-que-difere-a-pornografia-de-vinganca-dos-outros-crimese-a-continuidade/>. Acesso em 7 de abril de 2018. 
Nota-se, ainda, que as experiências afetivas envolvidas na prática de pornografia de vingança estão diretamente vinculadas às significações de feminilidade e masculinidade culturalmente construídas: no ódio do ex-parceiro que a expõe, no deleite de quem compartilha os materiais, no sofrimento da vítima e nos traumas psicológicos decorrentes da sua experiência, tem-se padrões emocionais estimulados pelas nossas regulações de gênero, pelos papeis e lugares atribuídos a homens e mulheres em nossa sociedade e, sobretudo, um campo de ação em que se legitima a objetificação do corpo feminino. Nesse caso, o campo afetivo é também marcado por essas relações de poder que instituem o orgulho do macho em função do domínio da mulher, asseverando o caráter relacional das diferenças de gênero percebido por Scott (1990).

O peso da visibilidade não consensual é, portanto, generificado: seus sentidos e suas motivações, efeitos e repercussões entre a "audiência" se explicam a partir das relações entre os gêneros. O sentido dessa prática lhes traz níveis distintos de desqualificação e depreciação entre homens e mulheres, assim como são variáveis as consequências às suas trajetórias de vida. Algo nesse sentido foi apontado em algumas matérias que abordaram a temática a partir das assimetrias de gênero que a fundam:

\begin{abstract}
Fruto de uma sociedade machista, a exposição de fotos ou vídeos íntimos, chamada de porn revenge, afeta sempre mais as mulheres do que os homens. "No caso do vazamento de imagens do ator Stênio Garcia e sua esposa, ficou evidente como é diferente a exposição e o trauma para homem e mulher", comenta a psicóloga Marcela Abreu, especialista em psicologia social. No episódio citado por Marcela, em que Stênio e sua esposa, Marilene Saade, tiveram uma foto de nu frontal compartilhadas nas redes sociais, os comentários em torno do tamanho e potência do órgão sexual do ator foram em tons elogiosos, enaltecendo a virilidade de um homem de quase 80 anos ${ }^{15}$.
\end{abstract}

Nesse caso, nem toda nudez é castigada. A atividade sexual masculina é não apenas normalizada, como também elogiável. As construções culturais em torno da corporeidade e sexualidade masculinas dão outro sentido à divulgação de conteúdos a elas relacionados. Mas, ainda que estejamos falando da permanência e/ou atualizações de formas históricas de poder, compreendemos que elas não são intransponíveis. Os territórios de opressão também são lugares de resistência, reação, novos protagonismos e deslocamentos. Logo, as condições sob as quais se prolifera a violência da pornografia de vingança podem possibilitar outras formas de interação e ações de enfrentamento, conforme já ilustramos. Não foram incomuns as reações que enfatizavam a necessidade de desconstrução das dinâmicas de culpabilização das vítimas da prática. Do mesmo modo, algumas delas utilizaram justamente as redes sociais como forma de reagir à violência sofrida em decorrência da violação de sua intimidade. Foi o caso da dinamarquesa Emma Holten que, aos 17 anos, teve suas fotos expostas pelo ex-namorado. Alguns anos depois, a jovem, que se tornou ativista do feminismo, convidou uma fotógrafa para realizar um ensaio em seu apartamento, registrando situações cotidianas em que aparecia nua. Dessa vez, as fotos foram publicadas por ela própria. O objetivo de Emma foi problematizar o lugar de culpa e de vergonha em que a nudez feminina é posta, estimulando um debate sobre consentimento e autonomia feminina e sobre o tipo de violência a que a mulher é exposta através da pornografia de vingança:

${ }_{15}$ Ver matéria “Porn revenge: sociedade precisa entender que a culpa não é das mulheres”, publicada em 18 de Janeiro de 2016. Disponível em http://arevistadamulher.com.br/sexo/content/2171930-porn-revenge-sociedade-precisa-entenderque-a-culpa-nao-e-das-mulheres $>$ Acesso em 7 de abril de 2018. 
Isso não é apenas para que eu me sinta melhor. É sobre problematizar e experimentar os papéis apresentados pela maioria das mulheres quando posam nuas. Nós dificilmente sorrimos, estamos no controle, vivemos. Nós nunca vemos, mas somos sempre vistas. [...] Consentimento é a chave. Assim como estupro e sexo não têm nada a ver, fotos compartilhadas com e sem consentimento são coisas completamente diferentes. Não há foto minha sexual, visual ou aceitável sem o meu consentimento. Sem a minha autorização há apenas violação ${ }^{16}$.

A história de Rose Leonel, criadora da ONG Marias da internet, também retrata a possibilidade de reação e empoderamento através dos próprios meios utilizados para a difamação da vítima. Rose teve fotos íntimas divulgadas pelo exnoivo que não aceitou o término do relacionamento, o que reforça o vínculo entre esse tipo de prática e a concepção patriarcal da subjetividade e corporeidade femininas como posses do homem, conforme já argumentamos em outras passagens.

Rose decidiu então mobilizar-se e transformar a própria experiência numa forma de ajudar outras vítimas.

\begin{abstract}
O objetivo [da ONG] é informar, orientar e dar suporte para as vítimas. Sou uma mulher que quer lutar por todas as outras mulheres. Isso me fortalece, me faz caminhar. Me sinto sendo útil erguendo essa bandeira, tendo essa missão [ressalta Rose]. Que bom seria se eu tivesse a oportunidade de conversar com todas as mulheres que passaram por isso. Quantas vidas seriam salvas, não é mesmo? [...] O objetivo é informar, orientar e dar suporte para as vítimas. Sou uma mulher que quer lutar por todas as outras mulheres. Isso me fortalece, me faz caminhar. Me sinto sendo útil erguendo essa bandeira, tendo essa missão [ressalta Rose]. Que bom seria se eu tivesse a oportunidade de conversar com todas as mulheres que passaram por isso. Quantas vidas seriam salvas, não é mesmo? ${ }^{17}$
\end{abstract}

Também podemos retomar como exemplo as outras iniciativas citadas anteriormente, pelas quais se prestam apoio psicológico e jurídico às vítimas. As redes sociais também se revelam, assim, como ferramentas de articulação, solidariedade, engajamento e questionamento de antigas violências. Sabemos, no entanto, que esses meios são marcados pelas disputas de mercado, o que envolve estratégias de monopolização e controle das informações, assim como os problemas das políticas de privacidade têm deixado os usuários cada vez mais expostos a esses interesses. Essas tecnologias não são politicamente isentas. Contudo, acreditamos que as formas de interação e articulação trazidas por elas sinalizam consequências igualmente inovadoras para o campo das relações sociais e das mobilizações, assim como evidenciam as barreiras de tempo e de espaço que a nossas tecnologias de comunicação mais recentes vêm desafiando. Assim, ainda que antigos valores se revelem bem assimilados por parte significativa das opiniões do público que consome e compartilha as notícias veiculadas a esses casos, e ainda que muitos dos conteúdos informativos não estimulem propriamente uma reflexão crítica e mais aprofundada sobre os mecanismos que significam e sustentam a prática de pornografia de vingança, os debates e disputas travados por meio das ferramentas de comunicação em rede reforçam a ideia de que outros discursos afloram em meio à reprodução das narrativas hegemônicas.

${ }_{16}$ Ver em < http://www.hypeness.com.br/2015/01/ativista-dinamarquesa-posta-fotos-nuas-para-combater-a-revengeporn/> Acesso em 7 de abril de 2018.

${ }_{17}$ Ver matéria "Fui assassinada', diz mulher que criou ONG contra 'vingança pornô", publicada em o8 de março de 2014 Disponível em <http://g1.globo.com/pr/norte-noroeste/noticia/2014/o3/fui-assassinada-diz-mulher-que-criou-ongcontra-vinganca-porno.html $>$. Acesso em 7 de abril de 2018. 


\section{Considerações finais}

As repercussões dos conteúdos que caracterizam a pornografia de vingança demarcam um voyeurismo que traz, a um só tempo, o fascínio e a repulsa em relação ao corpo feminino. Todos esses mecanismos têm em comum sua orientação por códigos sexistas que fazem da visibilidade feminina uma moeda de troca que circula conforme o desejo masculino. Um dos principais aspectos que nos chamaram a atenção nos conteúdos analisados foi a tendência a reduzir a questão a um problema de ordem privada e, sobretudo, feminina. Alguns dados sobre as campanhas preventivas e conscientizadoras, por mais que estimulassem um exercício empático e destacasse que princípios éticos são feridos por práticas como a que constitui nosso objeto de análise, elas nem sempre abordavam a questão a partir de uma perspectiva de gênero, embora quase sempre sejam direcionadas às mulheres. Muitas vezes elas têm como foco dicas de segurança para o uso das redes sem, no entanto, problematizar o próprio contexto em que essas campanhas se constituem como demandas urgentes.

Nossos dados revelam, além disso, a necessidade contínua de elaboração de políticas e ações educativas em torno da temática, junto às discussões sobre o que caracterizaria a cultura do estupro, pela qual a violência contra a mulher é quase sempre relativizada e justificada. Vê-se, portanto, que a discussão corre o risco de ser intimidada por abordagens que negligenciam a importância do debate sobre relações de gênero nas escolas, por exemplo. Do mesmo modo, não podemos desconsiderar que a objetificação do corpo feminino, ao ser problematizada a partir de outros marcadores sociais da diferença, como raça, por exemplo, revela experiências específicas da violência em torno da corporeidade e da sexualidade femininas. Os vestígios de uma cultura escravocrata mobilizam os modos pelos quais o corpo da mulher negra permanece subjugado por meio de processos concomitantes de desqualificação e hipersexualização que marcam a sua trajetória de vida. Assim, a compreensão dos mecanismos de criação e consumo de conteúdos compartilhados nas redes sociais digitais exige um olhar atento às assimetrias que têm sido institucionalizadas ao longo da nossa história, visto que as interações mediadas pelas plataformas comunicacionais em rede não se constituem como uma antítese radical dos vínculos estabelecidos presencialmente, conforme vimos argumentando.

Diante de tudo isso, consideramos que os usos das plataformas comunicacionais em rede se constituem como importante foco de análise das representações e embates em torno da corporeidade e sexualidade feminina, trazendo importantes reflexões sobre as relações de gênero que se estabelecem num cenário de supervalorização da performance de si no qual, entretanto, um modelo de sujeito continua exercendo seu domínio. A respeito de um corpo/sujeito a que historicamente a cidadania e as experiências na vida pública vêm sendo negadas, é preciso um olhar atento para os mecanismos pelos quais sua visibilidade é minada ou forjada. Por esse jogo de forças, a cena pública continua se configurando como ameaça ao corpo e à subjetividade feminina; segue como esfera em que sua dignidade é constantemente posta em xeque. 


\section{Referências}

DEBORD, Guy. A sociedade do espetáculo. Rio de Janeiro: Contraponto, 1997. FRAGOSO, Suely; RECUERO, Raquel; AMARAL, Adriana. Métodos de pesquisa para internet. Porto Alegre: Sulina, 2011.

GIONGO, Marina Grandi. Madalenas modernas e um caso de pornografia de vingança: reflexões sobre gênero, sexualidade e cidadania na educação. Porto Alegre: UFRGS, 2015.

LINS, Beatriz Accioly. "A Internet não gosta de mulheres? Gênero, sexualidade, e Violência nos debates sobre pornografa de vingança”. In: Anais da V Reunião Equatorial de Antropologia; XIV Reunião de Antropólogos Norte e Nordeste, 2015 .

MATOS, Maria Izilda. "Outras histórias: as mulheres e estudos dos gêneros - percursos e possibilidades”. In: SAMARA, Eni de Mesquita; SOHIET, Raquel; MATOS, M. Izilda S. (orgs.). Gênero em Debate: trajetória e perspectiva da historiografia contemporânea. São Paulo: EDUC, 1997. pp. 83-114.

MEDEIROS, Marcela; TAVARES, Marcelo. "Construção e validação de checklist de avaliação de risco de violência contra mulher nas relações de intimidade". In: STEVENS, C.; OLIVEIRA, S.; ZANELLO, V.; SILVA, E.; PORTELA, C. (orgs.). Mulheres e violências: interseccionalidades. Brasília: Technopolitik, 2017.

MILLER, Daniel; SLATER, Don. The Internet: An Ethnographic Approach. Paris: Berg, 2001.

MISKOLCI, Richard. Sociologia digital: notas sobre pesquisa na era da conectividade. Contemporânea, 6 (2): 275-297, 2016.

RIGONI, Ana; NUNES, Felipe; FONSECA, Katia. O culto ao corpo e suas formas de propagação na rede social facebook: implicações para a educação física escolar. Motrivivência, 29 (esp.): 126-143, 2017.

SAFFIOTI, Heleieth. Gênero Patriarcado Violência. São Paulo: Expressão Popular, 2015.

SCOTT, Joan. Gênero: uma categoria útil de análise histórica. Revista Educação e Realidade, 16 (2): 5-22, 1990.

VALENTE, Mariana Giorgetti; NERIS, Natália; RUIZ, Juliana Pacetta; BULGARELLI, Lucas. O Corpo é o Código: estratégias jurídicas de enfrentamento ao revenge porn no Brasil. InternetLab: São Paulo, 2016. 